\title{
Does imitation facilitate the acquisition of grammar? Evidence from a study of autistic, Down's syndrome and normal children*
}

\author{
HELEN TAGER-FLUSBERG \\ University of Massachusetts \\ AND \\ S USAN CALKIN S \\ University of Maryland \\ (Received 23 June 5989. Revised 20 November 1989)
}

\begin{abstract}
This paper re-opens the question of whether imitation plays a significant role in the acquisition of grammar. Data for this study came from four samples of naturalistic mother-child speech taken over the course of one year from four autistic, four Down's syndrome and four normal children, covering a range of MLU stages. In general, autistic children used more formulaic language, including imitations, than Down's syndrome children, who in turn used more than the normal children. Comparisons of imitative and spontaneous corpora from the same transcripts were made using MLU and the Index of Productive Syntax. The main findings were that, with few exceptions, spontaneous speech utterances were longer, and contained more advanced grammatical constructions than did the imitation utterances. These findings held across all three groups of subjects. We conclude that imitation does not facilitate grammatical development.
\end{abstract}

INTRODUCTION

What role does imitation play in the child's acquisition of language ? This question has been the focus of both theory and research, ever since some of the earliest work in the field (e.g. Jespersen, 1922). At various times quite opposite views and empirical findings have been reported in the literature

\footnotetext{
* This research was generously supported by a grant from the National Institute of Child Health and Human Development (ROI HD 18833). Portions of this study were presented at the 1986 Annual Convention of the American Psychological Association. We thank Gail Andrick, Ann Chadwick-Dias, and Karen Price for their help in preparing the transcripts. We also wish to extend our sincere appreciation to the children and their families who participated in this study. Address for correspondence : Helen Tager-Flusberg, Department of Psychology, University of Massachusetts, Boston, MA 02125, USA.
}

Tager-Flusberg, H. \& Calkins, S. (1990). Does imitation facilitate the acquisition of grammar? Evidence from a study of autistic, Down syndrome and normal children. Journal of Child Language, 17, 591-606.

Made available courtesy of Cambridge University Press 
and there is still no resolution to the conflict. In this paper we focus on one aspect of the imitation and language development debate : are children's full or partial imitations in naturalistic speech relevant to the process of acquiring grammatical structure ?1

Skinner (1957) attributed a key role to imitation which, together with reinforcement, was used to explain how the environment came to shape the ' verbal behaviour' of the child toward the adult model. Within a learning theory account of language acquisition such as Skinner's, the input language is crucially important in the acquisition process, and the child's output could be predicted directly from the speech to which he or she was exposed. The psycholinguistic revolution of the early 196os radically changed our conceptions of language and the language acquisition process. With the advent of Chomsky's transformational theory (Chomsky, 1957), language was now conceived of as rule-governed, with underlying structure that could not be recovered directly from the surface. On this view, children's language development was conceptualized in quite different ways from traditional learning theory, as the acquisition problem was now defined in terms of acquiring a productive rule system that would generate the grammatical sentences of a child's native language. Since the rule system, or grammar, to be acquired is not transparently given in the input, the significance of input for language development was diminished and imitation was no longer considered to facilitate development. Thus the pendulum swung away from the view that imitation is an important process in language acquisition.

Studies of child language began in earnest at this time in support of this new theoretical perspective. Evidence was gathered showing that at the early stages of development children said things quite differently from adults, and that they were indeed acquiring productive rule systems (see, for example, Bellugi \& Brown, 1964). Research on imitation in spontaneous speech demonstrated that it was not frequent, nor was it grammatically more advanced than non-imitated speech (Ervin, 1964). Based on her study of imitation in the speech of five children, Ervin concluded that there is not a shred of evidence supporting a view that progress toward adult norms of grammar arises merely from practice in overt imitation of adult sentences' (1964: 172).

By the mid 1970s the pendulum began to swing back toward attributing to imitation a more significant role in language acquisition. Cracks had appeared in the original form of the transformational perspective (e.g. Fodor,

[I] In this article we will not address research on delayed or expanded imitation. There are a number of methodological questions about how to define delayed imitation without very detailed diary data of both the child's language and the parental input. Expanded imitations are also difficult to define and may well serve quite different functions from exact or reduced imitations.

Tager-Flusberg, H. \& Calkins, S. (1990). Does imitation facilitate the acquisition of grammar? Evidence from a study of autistic, Down syndrome and normal children. Journal of Child Language, 17, 591-606. Made available courtesy of Cambridge University Press 
Bever \& Garrett, 1974); numerous studies were interpreted as demonstrating that the language spoken to children was more important in the process of development than had previously been thought (e.g. Snow, 1972); and the significance of individual differences in language development began to be recognized (e.g. Nelson, 1973; Bloom, Lightbown \& Hood, 1975). It was within the climate of these theoretical shifts that new studies of imitation were undertaken. As before, the studies designed to investigate the role of imitation examined whether children imitated certain syntactic or morphological forms before they produced those forms in non-imitative, or spontaneous speech.

One of the most detailed quantitative studies of imitation was conducted by Bloom and her colleagues (Bloom, Hood \& Lightbown, 1974). They compared the imitative and non-imitative speech of six children who were in the earliest stages of grammatical development (MLUs between $\bullet 0$ and $2 \bullet 0)$. They found significant individual variation in the degree of imitation exhibited by their subjects : three of the subjects were consistently high imitators, two were consistently low, and one child changed from high to low between the first and second observation. Because two of the children hardly imitated at all during this early period of grammatical development, Bloom et al. concluded that 'imitation is not required behaviour for learning to talk' (i974: 387). Nevertheless, they did find that in the high imitators, imitation was selective. Only certain structures were selected by the child for imitation typically structures that contained elements (for example lexical terms) that the child had already acquired, and new elements that soon after emerged in spontaneous speech. Bloom et al. also found in the high imitators that the MLU for imitated utterances was equal to or higher than the MLU for nonimitative utterances. Thus Bloom et al. argued that for these children, imitation appeared to play a role in language acquisition, reflecting the active processing of linguistic information about which the child had already developed some knowledge and understanding.

Moerk (1977) extended the findings from Bloom et al. to two older children whose MLU ranged from 2.4 to 3.5. In his study Moerk found that imitative utterances from his subjects were more advanced than their nonimitative utterances, although the MLU of imitative utterances was significantly lower than the MLU of non-imitative utterances, contradicting Bloom et al.'s findings for younger children. Still, Moerk interprets his data as support for the view that imitation continues to play a significant role beyond the earliest stages of development. Because Moerk does not provide any indication of the proportion of speech that was imitative in his subjects, we do not know whether his findings, like Bloom et al.'s, are restricted to high imitators, or whether they extend to low imitators too. There are a number of problems with Moerk's study that limit the reliability of his conclusions. First, his language recordings depended

Tager-Flusberg, H. \& Calkins, S. (1990). Does imitation facilitate the acquisition of grammar? Evidence from a study of autistic, Down syndrome and normal children. Journal of Child Language, 17, 591-606. Made available courtesy of Cambridge University Press 
primarily on observers, note-taking and were only sporadically supplemented by tape recordings of the children's speech. The children were recorded in play together with a babysitter - a context quite different from the usual ways in which language samples are taken. In his quantitative analyses, Moerk relied on very small samples (for one subject, 38 utterances; for the other subject, 5o utterances) of both imitative and non-imitative speech. Furthermore, while the imitative utterances were pooled across the six months the children were followed, only three samples of spontaneous speech from different points in time were selected and separately analysed. Thus comparisons of imitative and non-imitative speech were not taken from comparable time periods, nor, in fact, could the temporal relationship between the use of forms in imitation versus spontaneous speech be examined. Finally, only a small number of grammatical structures were selected for analysis and no rationale was provided for why these particular ones were chosen. ${ }^{2}$ Thus both the methodology and the analyses in Moerk's study raise doubts about the conclusions he has drawn from his data.

More recently, Stine \& Bohannon (1983) studied the use of imitation in one child whose MLU was beyond 3.5, at two points in time : when the child was $2 ; 8$ and then when he was 3 ; o. Despite the fact that Stine $\&$ Bohannon's subject was a very low imitator, they state that his imitations were also progressive, that is certain forms appeared first in imitations and only later in his spontaneous speech. Unfortunately, because there is no detailed presentation of the child's non-imitative utterances, these claims cannot be confirmed from the paper. There are also methodological problems with this study that limit the generalizability of its findings. The most serious problem is again the context in which the language samples were taken. The subject was observed at two different time periods, with a total of 2 i different adults, sometimes in groups, only one of whom (the mother) knew the child before the taping began. Because the vast majority of the child's imitations were obtained in conversation with virtual strangers, in this context imitation was most likely a signal of perceptual difficulties; thus these data cannot be taken as evidence about the child's linguistic knowledge.

We see, therefore, that apart from Bloom's study of very young children, the research that has utilized quantitative analyses to investigate the role of imitation in language acquisition has not provided unequivocal evidence in favour of attributing a significant role to imitation in the process of grammatical development. Nevertheless, a number of other reports in the literature, more anecdotal and qualitative in nature, support the findings of Bloom et al. (1974), Moerk (1977) and Stine \& Bohannon (1983). Snow

[2] Elsewhere Pinker (1980 has criticized Moerk (t 980) for analogous flaws in his selective choice of items for analysing the relationship between input frequency and the acquisition of grammatical morphemes.

(1981) discusses a number of examples of imitation from her own son ; however, she emphasizes the significance of expanded and delayed imitations

Tager-Flusberg, H. \& Calkins, S. (1990). Does imitation facilitate the acquisition of grammar? Evidence from a study of autistic, Down syndrome and normal children. Journal of Child Language, 17, 591-606. Made available courtesy of Cambridge University Press 
rather than immediate non-expanded imitations. Similarly, Clark (1977, 1978), using anecdotal evidence of the widespread use of different types of imitations in the speech of two children, concludes that imitation is of crucial importance in the acquisition of grammar. Finally, the same kinds of arguments are presented in Reger's (1986) analysis of the early stages of Hungarian language development in two children, although her focus is more on the discourse role of imitation than on how it serves grammatical development.

The weight of evidence in the literature since the early 1970s heavily favours ascribing imitation a role in language development. Researchers differ on what kind of role imitation plays : at one end Bloom et al. (1974) consider imitation of limited significance, and only so for some children, i.e. those who are high imitators ; at the other end Stine \& Bohannon (1983), Clark (1977) and Moerk (1980) argue that imitation is a central process in language development, probably for all children.

There is particular interest in the potential role played by imitation in language acquisition among researchers who study children with language disorders. It has been noted that children with a variety of impairments that result in delays in language development, ranging from blindness (Peters, 1987), to retardation (Dooley, 1976; Fowler, 1984), to autism (Simon, 1975; Prizant, 1983), exhibit relatively high rates of imitation. In general, although children with these kinds of disorders are slow in acquiring language, it is assumed that imitation plays a facilitative role, especially in their grammatical development.

In the current literature on both normal and disordered child language, the role of imitation is placed within the context of individual differences in the process of acquiring language. Peters (1977, 1983), for example, has argued that children fall into two broad groups : those who approach language ANALYTICALLY and those whose approach IS HOLISTIC or GESTALT (see also Bretherton, McNew, Snyder \& Bates, 1983 ; Bates, Bretherton \& Snyder, 1988). Children who imitate a lot and rely on other kinds of ' formulaic ' language such as routines and repetitions, including children with disorders, represent the latter group (cf. Prizant, 1983).

The goal in this paper is to re-open the question of whether imitation facilitates grammatical development, by comparing imitative and non-imitative utterances in the conversational speech of children who are likely to be relatively high imitators : autistic children and children with Down's syndrome. We also included a control group of normally developing children who were matched to the other two groups on MLU. In this way we were able to study a relatively large number of subjects who covered a range of individual differences in imitation as well as in non-linguistic social and

Tager-Flusberg, H. \& Calkins, S. (1990). Does imitation facilitate the acquisition of grammar? Evidence from a study of autistic, Down syndrome and normal children. Journal of Child Language, 17, 591-606. Made available courtesy of Cambridge University Press 
cognitive abilities. For all the children, language samples collected over the course of one year were included in our analyses. We used two types of measures to compare imitative and spontaneous utterances. In order to resolve the conflicting findings in the literature on MLU, we compared the length of imitative and non-imitative utterances. Our second measure, the Index of Productive Syntax - IPSyn (Scarborough, 1985, 199o), was used to compare directly the syntactic and morphological structures used in both imitative and spontaneous utterances, in order to test the hypothesis that structures will be used first in imitation and then in spontaneous speech. These measures allowed us to make comprehensive and objective comparisons between imitative and spontaneous speech, rather than making a biased selection of particular constructions. By taking samples of speech across a one-year span, we were able to investigate systematically the relationship between constructions used in imitative and spontaneous speech.

\section{METHOD}

Subjects

The 12 subjects for this study were four autistic children, four children with Down,s syndrome, and four normally developing children. The autistic and Down's syndrome children and one of the normal children were all part of a larger study of language acquisition in these populations (TagerFlusberg, Calkins, Nolin, Baumberger, Anderson \& Chadwick-Dias, 1990); the other three normal children were Adam, Eve and Sarah, whose language samples were collected and transcribed by Brown and his colleagues (Brown, 1973).

The four autistic subjects were all males who had been diagnosed using the criteria of the Diagnostic and Statistical Manual of Mental Disorders, third edition (DSM- III, American Psychiatric Association, 1980). These criteria include : onset prior to 2;6; impairments in social relationships and socialization; delays and deficits in acquiring language and communication ; and obsessive, compulsive or repetitive behaviour patterns. The children lived at home with their families and either participated in a home-intervention program or attended special day-school programs serving autistic children. The IQ scores of the autistic subjects were assessed using the Leiter International Performance Scale : a non-verbal measure of intelligence. Three of the autistic children were in the normal range of intellectual functioning (IQs between 91 and 105), while the fourth had a measured IQ of 61 . Their mean age was $4 ; 7(3 ; 4-6 ; 9)$, and their mean MLU (excluding imitation, repetition and routine utterances) at the start of the study was 2-07 (1.16-3.03).

The Down's syndrome children, three males and one female, were located through hospital records. They were comparable to the autistic children in

Tager-Flusberg, H. \& Calkins, S. (1990). Does imitation facilitate the acquisition of grammar? Evidence from a study of autistic, Down syndrome and normal children. Journal of Child Language, 17, 591-606.

Made available courtesy of Cambridge University Press 
their family and educational backgrounds, and on SES (all the children were middle-class). They were, however, lower than the autistic children in IQ (ranging from 47 to 63) and mental age, and somewhat older as a group (mean age $=5 ; 8 ; 5 ; 1-6 ; 9)$. Their average MLU at the start of the study was 2.33 $(-63-2.69)$.

The normal children's language samples were selected to cover the same range in MLU at the start of the study as both disordered groups. Their mean MLU was 2.46 (1-99-2-94). They were, of course, significantly younger than any of the children in the other groups with their average age of $2 ; 2$ $(1 ; 9.2 ; 8)$.

\section{Collection and preparation of language samples}

Language samples were collected from the children while they interacted with their mothers during regular visits by researchers to their homes. Details about the procedures used by Brown and his colleagues for three of the normal children can be found in Brown (1973). Computer text files of their transcripts were made available by CHILDES (McWhinney \& Snow, 1985). The language samples for the disordered children and the fourth normal child were collected in comparable ways during bi-monthly home visits lasting about one hour (for more details see Tager-Flusberg et al. 1990). Transcripts were prepared in the form of computer files, using the SALT format (Miller \& Chapman, 1985), with both audiotapes and videotapes providing context notes on the ongoing activity.

\section{Coding of utterances}

For each child, four complete language samples taken from four-monthly intervals were selected for coding and analysis, thus covering a period of one year. The children's utterances were coded into the following categories in order to obtain from each sample a corpus of rich spontaneous speech utterances, and corpora of imitative and other forms of formulaic speech (routines and self-repetitions):

(1) Unintelligible: Utterances that were incomplete, completely or partially unintelligible, or composed of non-linguistic sounds.

(2) Yes/no: Utterances that were one-word responses, yes/no or their equivalents.

(3) Proper name: One word utterances consisting of a proper name.

(4) Routine: Utterances consisting of songs, routine games (e.g. ' seesaw '), social routines (e.g. thank you, happy birthday, you, re welcome), book reading, counting, commercials (usually from television), or other routines in which mother and child frequently engaged.

Tager-Flusberg, H. \& Calkins, S. (1990). Does imitation facilitate the acquisition of grammar? Evidence from a study of autistic, Down syndrome and normal children. Journal of Child Language, 17, 591-606. Made available courtesy of Cambridge University Press 
(5) Self-repetition: Utterance is a repetition of child's own prior utterance, excluding any of the above categories. One or more of mother's utterances may intervene.

(6) Imitation: Utterance is an imitation of mother's utterance, including immediate or delayed (within five transcript lines) full or partial imitations, in which the child's utterance was an exact or reduced (some morphemes deleted) imitation of the mother's prior utterance with no morphemes added.

(7) Spontaneous : Utterances not classified in any of the above categories.

Represents a novel, non-imitative child utterance.

Five of the 48 transcripts (about $10 \%$ ) were coded separately by a second coder and reliability was $93 \%$.

\section{RESULTS}

The data were first analysed to test whether children with autism and Down's syndrome are indeed more likely to use formulaic language than normally developing children. Table I presents the mean proportions of total child

TABLE I. Mean proportions of imitations, repetitions, routines and spontaneous speech in samples from autistic, Down's syndrome and normal children

\begin{tabular}{|c|c|c|c|}
\hline & Autistic & Down's syndrome & Normal \\
\hline \multicolumn{4}{|l|}{ Imitations } \\
\hline \multirow{5}{*}{$\begin{array}{r}\text { Sample } 1 \\
2 \\
3 \\
4 \\
M\end{array}$} & 0.184 & 0.074 & 0.103 \\
\hline & 0.139 & 0.108 & 0.040 \\
\hline & 0.101 & 0.092 & 0.016 \\
\hline & 0.130 & 0.065 & 0.019 \\
\hline & 0.138 & 0.084 & 0.044 \\
\hline \multicolumn{4}{|l|}{ Repetitions } \\
\hline I & 0.134 & 0.033 & 0.032 \\
\hline 2 & 0.095 & 0.056 & 0.025 \\
\hline 3 & 0.089 & 0.052 & 0.020 \\
\hline 4 & 0.073 & 0.056 & 0.013 \\
\hline$M$ & 0.098 & 0.049 & 0.023 \\
\hline \multicolumn{4}{|l|}{ Routines } \\
\hline $\begin{array}{l}\text { I } \\
2\end{array}$ & $\begin{array}{l}0.083 \\
0.068\end{array}$ & 0.105 & 0.024 \\
\hline 3 & $\begin{array}{l}0.068 \\
0.158\end{array}$ & $\begin{array}{l}0.072 \\
0.044\end{array}$ & $\begin{array}{l}0.036 \\
0.055\end{array}$ \\
\hline 4 & 0.088 & 0.049 & 0.031 \\
\hline$M$ & 0.099 & 0.067 & 0.037 \\
\hline \multicolumn{4}{|l|}{ Spontaneous } \\
\hline I & 0.295 & 0.312 & 0.505 \\
\hline 2 & 0.428 & 0.339 & 0.676 \\
\hline 3 & 0.445 & 0.497 & 0.677 \\
\hline 4 & 0.410 & $0.54 \mathrm{I}$ & 0.657 \\
\hline$M$ & 0.395 & 0.422 & 0.629 \\
\hline
\end{tabular}

Tager-Flusberg, H. \& Calkins, S. (1990). Does imitation facilitate the acquisition of grammar? Evidence from a study of autistic, Down syndrome and normal children. Journal of Child Language, 17, 591-606.

Made available courtesy of Cambridge University Press 
utterances for each group, that were categorized as spontaneous, imitation, repetition, or routine, separately for each sample.

Two-way analyses of variance were conducted on each of these utterance categories with sample as a repeated measures factor and group as a between subjects variable. For spontaneous utterances, both group $(F(2,9)=5.9$, $p<0.02)$ and sample $(F(3,27)=13 \bullet 03, p<0 \bullet 001)$ were significant, but the group by sample interaction was not $(F(6,27)=2 \bullet 01)$. In general spontaneous speech increased over successive samples during the course of the year. From Table 1 it is clear that autistic children were the least spontaneous while the normal children were the most. For each of the categories representing formulaic speech (imitations, repetitions and routines) the opposite pattern was found with autistic children using the highest proportion and the normal children the lowest. Group was a significant factor for both routines $(F(2,9)=3 \bullet 79, \mathrm{p}<0.06)$ and repetitions $\left(F_{(2,9)}=25-45\right.$, $p<0.00)$ but did not reach significance for imitation $(F(2,9)=2.83)$. Sample was a significant variable only for imitations, which decreased over the course of the year, $F(3,27)=5-47, p<0.005$.

In general, these results confirm the picture of autistic children using relatively high amounts of formulaic language, while the normal subjects in this sample were much less likely to do so. The Down's syndrome children fell between these two groups. Thus the 12 subjects in this study covered a range of individual differences in the amounts of imitative and other types of formulaic language that they used in their speech.

The data were then analysed to answer the central question addressed in this paper, that is whether imitative speech is linguistically more advanced than spontaneous speech. Because MLU (Brown, 1973) and IPSyn (Scarborough, 199o) are measures designed to be computed on samples of 100 utterances, for each transcript the first 100 spontaneous and too imitative utterances were assembled. Although almost all the spontaneous corpora contained a full 100 utterances, the imitation corpora were smaller ranging from 1 to 88 utterances across the 12 children in the study.

MLUs were computed for the corpora of spontaneous and imitative utterances and these data are presented in Figure 1. The graph illustrates that, averaged across children within each group, MLU for spontaneous speech is always higher than for imitative speech. Looking at the individual subject data, we find that of 16 samples from the autistic subjects, imitation MLU was higher than spontaneous MLU in only three samples. The corresponding figures for the Down's syndrome and normal subjects were nil and two respectively. Using a Wilcoxon matched-pairs signed ranks test, the difference between imitation and spontaneous MLU was highly significant for all groups (autistic : $T=12, p<0.002$; Down's syndrome : $T=o$,

Tager-Flusberg, H. \& Calkins, S. (1990). Does imitation facilitate the acquisition of grammar? Evidence from a study of autistic, Down syndrome and normal children. Journal of Child Language, 17, 591-606. Made available courtesy of Cambridge University Press 
$p<0.0002$; normal : $T=3, p<0.0005)$, suggesting that MLU for spontaneous speech is significantly higher than for imitative speech.

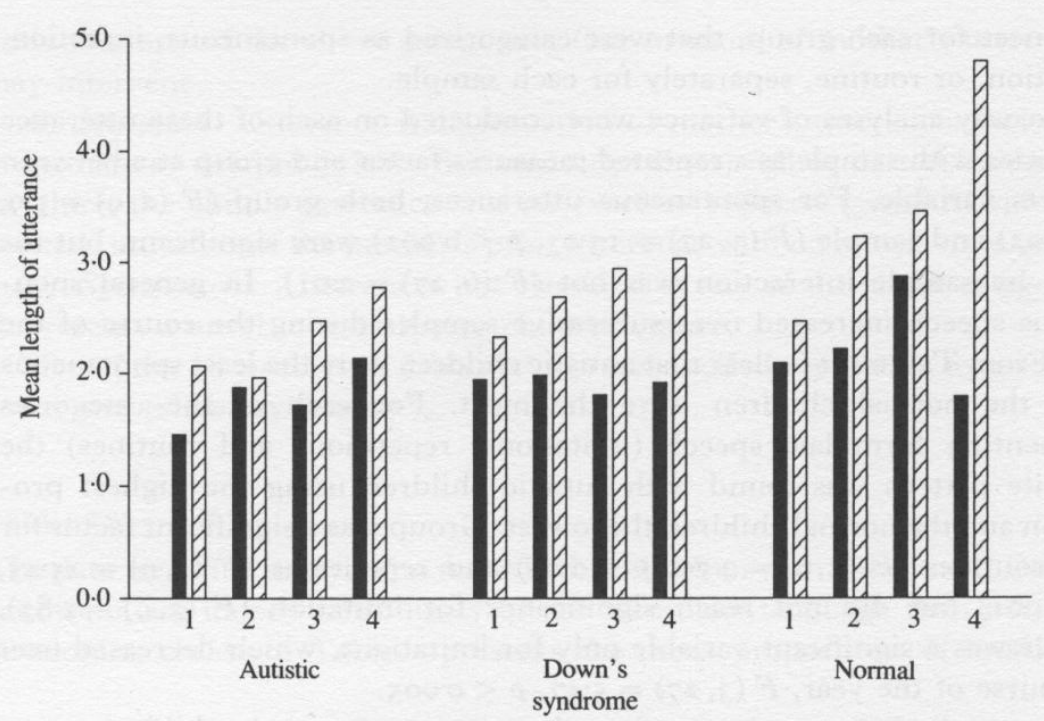

Fig. I. MLU in imitative and spontaneous speech for autistic, Down's syndrome, and normal subjects. Imitation; $\square$ spontaneous.

Another way to investigate whether imitation is more advanced than spontaneous speech, is to compare the grammatical content of both sets of corpora. This was done using IPSyn, which charts the emergence of a broad range of 56 syntactic and morphological structures in four categories : noun phrase (NP), verb phrase (VP), question/negation (QN), and sentence structure (SS). Within each category, items are ordered developmentally and the occurrence of zero, one, or two different examples of each item are noted and awarded the corresponding points. Appendix A lists the items in order for each of the IPSyn categories. Instead of using the IPSyn in the standard way, by comparing the total number of points in the imitation and spontaneous corpora, we took advantage of the developmental ordering of the items. For each corpus the highest item used within each category was identified, and the comparison between imitation and spontaneous corpora focused on the developmental level of the structures used in both. For example, in the NP category, if the highest or maximum item used in one corpus was a plural, it would be scored N7 (see Appendix A); while the highest item in the other matched corpus, e.g. an article, would be scored maximum N5. The corpus with the maximum score of N7 was then identified

Tager-Flusberg, H. \& Calkins, S. (1990). Does imitation facilitate the acquisition of grammar? Evidence from a study of autistic, Down syndrome and normal children. Journal of Child Language, 17, 591-606.

Made available courtesy of Cambridge University Press 
as being at the more advanced level. In this way we could compare the developmental level of particular grammatical constructions used in imitation and spontaneous speech in each of the categories : NP, VP, QN, and SS.

The imitation and spontaneous corpora were coded separately using the

TABLE 2. Comparison of maximum IPSyn scores in imitation and spontaneous speech corpora for autistic, Down's syndrome and normal children

\begin{tabular}{|c|c|c|c|}
\hline & Autistic & Down's syndrome & Normal \\
\hline \multicolumn{4}{|l|}{ NP } \\
\hline Imitation $>$ spontaneous & 2 & $\circ$ & 2 \\
\hline Imitation $=$ spontaneous & 6 & 5 & 0 \\
\hline Imitation $<$ spontaneous & $8^{*}$ & II $\mathrm{I}^{* * *}$ & $14^{* *}$ \\
\hline \multicolumn{4}{|l|}{ VP } \\
\hline Imitation $>$ spontaneous & 2 & $\circ$ & $\circ$ \\
\hline Imitation $=$ spontaneous & 3 & 3 & o \\
\hline Imitation $<$ spontaneous & II** & I $3 * * *$ & $16 * * *$ \\
\hline \multicolumn{4}{|l|}{ QN } \\
\hline Imitation $>$ spontaneous & 2 & 2 & ○ \\
\hline Imitation $=$ spontaneous & 3 & 3 & 2 \\
\hline Imitation $<$ spontaneous & I I** & II** & $14 * * *$ \\
\hline \multicolumn{4}{|l|}{ SS } \\
\hline Imitation $>$ spontaneous & 2 & I & $\circ$ \\
\hline Imitation $=$ spontaneous & 2 & I & 0 \\
\hline Imitation $<$ spontaneous & I $2 * *$ & $14^{* * * *}$ & $16 * * *$ \\
\hline \multicolumn{4}{|l|}{ OVERALL } \\
\hline Imitation $>$ spontaneous & 8 & 3 & 2 \\
\hline Imitation $=$ spontaneous & 14 & 12 & 2 \\
\hline Imitation $<$ spontaneous & $42^{* * *}$ & $49^{* * *}$ & $60 * * *$ \\
\hline
\end{tabular}

IPSyn scheme outlined above, and for each sample the maximum IPSyn scores within each category used in imitation and spontaneous speech were compared. Table 2 shows the number of transcripts in which the maximum IPSyn score for imitation was higher than, equal to, or lower than the maximum score in spontaneous speech. The differences between imitation and spontaneous maximum IPSyn were all significant, using a Sign test. These results confirm the analyses of the MLU data indicating that the grammatical structure of spontaneous speech is significantly more advanced than imitation speech, for all the groups of children in this study.

Even though only 13 of the 192 possible comparisons presented in Table 2 revealed higher maximum IPSyn scores in imitation than in spontaneous speech, we examined the data to see whether there were any relationships between MLU, amount of imitative speech, and such use of

Tager-Flusberg, H. \& Calkins, S. (1990). Does imitation facilitate the acquisition of grammar? Evidence from a study of autistic, Down syndrome and normal children. Journal of Child Language, 17, 591-606.

Made available courtesy of Cambridge University Press 
novel structures in imitation. Of the 12 children in the study, eight (four autistic, two Down,s syndrome and two normal) had at least one example where the maximum IPSyn score within a category was higher in imitation than in spontaneous speech. The starting MLUs for these eight children were lower than for the four children who had no such examples : $M=$ 2'12 compared to $M=2.62$. They also used proportionately more imitative speech : $M=11.2 \%$ com-

pared to $M=4.3 \%$. This suggests that children with lower MLUs and a relatively higher proportion of imitative language are somewhat more likely to use novel structures in imitation. However these findings are based on a very small number of such examples and therefore are not very reliable.

Finally, we examined the data for evidence that constructions first used in imitation would later appear in spontaneous speech. Of the 13 such examples, six were used in spontaneous speech in the following language sample, but seven never appeared in later samples of spontaneous speech. Thus our findings on the temporal relationship between imitation and spontaneous speech are equivocal at best.

\section{DISCUSSION}

The results of this study suggest that across a broad range of children, including some with disorders in language acquisition, imitated speech is neither longer nor grammatically more advanced than non-imitated, spontaneous speech. Despite the very small number of exceptions to these overall results, our conclusion is that imitation does not facilitate grammatical development in normal, Down's syndrome or autistic children.

These findings are consistent with some of the earlier literature on normally developing children, including Ervin (1964), and Kemp \& Dale (1973). However they contradict more recent work, such as Moerk (1977) and Stine \& Bohannon (1983), indicating support for our critique of these two studies in the introduction to this paper. The dominant pattern of empirical findings, then, is that imitation is not progressive and therefore cannot be considered to play as important a role in grammatical development as has been argued by a number of prominent researchers (e.g. Moerk, 1977; Clark, 1978 ; Snow, 1981 ; Peters, 1983 ; Bates et al. 1988 ; Bohannon \& Warren-Leubecker, 1989).

Like Bloom et al. (1974), we did find a few samples with longer imitation MLU, and isolated examples of linguistic constructions used first in imitation in children with the lowest MLUs and highest rates of formulaic language in the study. Similar results on length of utterances were also obtained by Rondal (1980) for children with

Tager-Flusberg, H. \& Calkins, S. (1990). Does imitation facilitate the acquisition of grammar? Evidence from a study of autistic, Down syndrome and normal children. Journal of Child Language, 17, 591-606. Made available courtesy of Cambridge University Press 
Down,s syndrome, and in a study of autistic children's echolalia by Howlin (1982). This suggests that perhaps at the earliest stages of language development some children rely heavily on imitation, using some grammatical structures that they have not yet acquired. Unlike Bloom et al. we found no evidence in our data for the progressive nature of imitation ; that is, there was no systematic pattern among the children of particular structures that were used in this way, nor did we find that these structures always appeared soon after in spontaneous speech. Perhaps this was because we focused on syntactic and morphological constructions whereas Bloom and her colleagues analysed the emergence of semantic relations in their young subjects. Even if we take our exceptional examples of more advanced imitation into consideration, the weight of evidence from this study as well as others in the literature demonstrates that imitation could only play a very limited role in grammatical development for a relatively small number of children.

If imitation is not a significant process in grammatical development, what other functions does it serve in language acquisition, especially for those children who are frequent imitators, including children with autism ? Studies of both normal (e.g. Bloom, Rocissano \& Hood, 1g76; Casby, 1986) and impaired children (e.g. Tager-Flusberg, 1982) suggest that for these children imitation is an important strategy for keeping a role in ongoing conversation, especially as a means for maintaining topic relevance. The finding that imitation is more prevalent in children at the early stages of language development who have more limited means of expression provides support for this approach of ascribing imitation an important communicative function. There is also some evidence that imitation may facilitate lexical and phonological development in a wide range of children (e.g. Peters, 1977; Coggins \& Morrison, 1981) but there have been fewer investigations in these areas. Because the acquisition of vocabulary and phonology is so dependent on the input to the child, it would not be surprising to find that imitation plays a role in their development.

There has been a growing interest in recent years in individual differences in language acquisition, including both normally developing children and impaired populations. Evidence regarding a broad range of differences that are found among children has opened up the theoretical debate on whether there is more than one pathway that children follow in acquiring language, particularly in the domain of grammatical development (e.g. Nelson, 1981; Hardy-Brown, 1983 ; Peters, 1983 ; Snow \& Bates, 1984 ; Bates et al. 1988). The important question is the extent to which individual differences that have been identified by researchers reflect genuine differences in the PROCESS by which syntactic or

Tager-Flusberg, H. \& Calkins, S. (1990). Does imitation facilitate the acquisition of grammar? Evidence from a study of autistic, Down syndrome and normal children. Journal of Child Language, 17, 591-606. Made available courtesy of Cambridge University Press 
morphological rules are acquired or whether they reflect other aspects of language functioning such as style, cognitive or social competence, that have no bearing on grammatical development. Individual differences in imitation have played a central role in this debate. Based on the findings presented in this paper, we argue that there is no evidence for the claim that individual differences in imitation reflect deep differences in the ways in which language is acquired. The similarities between the subjects from diverse populations, who are at quite different levels of cognitive and social functioning, suggest that there is significant uniformity in the way at least grammatical aspects of language are acquired. It remains to be seen whether there are other dimensions of individual differences in language that are more directly linked to divergent routes and processes in the acquisition of language.

\section{REFERENCES}

Bates, E., Bretherton, I. \& Snyder, L. (1988). From first words to grammar : individual differences and dissociable mechanisms. New York. C.U.P.

Bellugi, U. \& Brown, R. (eds) (1964). The acquisition of language. Monographs of the Society for Research in Child Development 29. No. 92.

Bloom, L., Hood, L. \& Lightbown, P. (1974)• Imitation in language development : if, when, and why. Cognitive Psychology 6. 380-420.

Bloom, L., Lightbown, P. \& Hood, L. (1975). Structure and variation in child language. Monographs of the Society for Research in Child Development 40. No. 160.

Bloom, L., Rocissano, L. \& Hood, L. (1976). Adult-child discourse: developmental interaction between information processing and linguistic knowledge. Cognitive Psychology 8. 521-52.

Bohannon, J. N. \& Warren-Leubecker, A. (1989). Theoretical approaches to language acquisition. In J. B. Gleason (ed.), The development of language. Second edition. Columbus, OH: Merrill.

Bretherton, I., McNew, S., Snyder, L. \& Bates, E. (1983). Individual differences at zo months: analytic and holistic strategies in language acquisition. Journal of Child Language 10. 293-320.

Brown, R. (1973). A first language. Cambridge, MA: Harvard University Press.

Casby, M. W. (1986). A pragmatic perspective of repetition in child language. Journal of Psycholinguistic Research i5. 127-40.

Chomsky, N. (1957). Syntactic structures. The Hague: Mouton.

Clark, R. (1977). What,s the use of imitation ? Journal of Child Language 4. 341.59(1978). Some even simpler ways to learn to talk. In N. Waterson \& C. Snow (eds), The development of communication. London : Wiley.

Coggins, T. E. \& Morrison, J. A. (1981). Spontaneous imitations of Down,s syndrome children : a lexical analysis. Journal of Speech and Hearing Research 24. 3०3-7.

Dooley, J. (1976). Language acquisition and Down,s syndrome : a study of early semantics and

syntax. Unpublished doctoral dissertation, Harvard University.

Ervin, S. (1964). Imitation and structural change in children,s language. In E. Lenneberg (ed.), New directions in the study of language. Cambridge, MA: M.I.T. Press.

Fodor, J., Bever, T. \& Garrett, M. (1974). The psychology of language : an introduction to psycholinguistics and generative grammar. New York: McGraw Hill.

Fowler, A. (1984). Language acquisition of Down,s syndrome children : production and comprehension. Unpublished doctoral dissertation, University of Pennsylvania.

Hardy-Brown, K. (1983). Universals and individual differences: disentangling two ap-

proaches to the study of language acquisition. Developmental Psychology 19. 610-24.

Howlin, P. (1982). Echolalic and spontaneous phrase speech in autistic children. Journal of

Tager-Flusberg, H. \& Calkins, S. (1990). Does imitation facilitate the acquisition of grammar? Evidence from a study of autistic, Down syndrome and normal children. Journal of Child Language, 17, 591-606. Made available courtesy of Cambridge University Press 
Child Psychology and Psychiatry 23. 281-93.

Jespersen, 0. (1922). Language : its nature, development, and origin. London: George Allen \& Unwin.

Kemp, J. \& Dale, P. (1973). Spontaneous imitation and free speech: a grammatical comparison. Paper presented at the Society for Research in Child Development, Philadelphia, Pennsylvania.

McWhinney, B. \& Snow, C. (1985). The child language data exchange system. Journal of Child Language 12. 271-95.

Miller, J. \& Chapman, R. (1985). Systematic analysis of language transcripts : user's guide. Madison, WI: University of Wisconsin, Language Analysis Laboratory.

Moerk, E. L. (1977). Processes and products of imitation : additional evidence that imitation is progressive. Journal of Psycholinguistic Research 6. 187-202.

(1980). Relationships between parental input frequencies and children,s language acquisition: A reanalysis of Brown,s data. Journal of Child Language 7. 105-18.

Nelson, K. (1973). Structure and strategy in learning to talk. Monographs of the Society for Research in Child Development 38. No. 149.

(1981). Individual differences in language development : implications for development and language. Developmental Psychology 17. 170-87.

Peters, A. M. (1977). Language learning strategies: does the whole equal the sum of the parts ? Language 53. 560-73.

(1983). The units of language acquisition. New York : C.U.P.

(1987). The role of imitation in the developing syntax of a blind child. Text 7. 289-311.

Pinker, S. (1981). On the acquisition of grammatical morphemes. Journal of Child Language 8. 477-84.

Prizant, B. (1983). Language acquisition and communication behavior in autism : toward an understanding of the whole, of it. Journal of Speech and Hearing Disorders 48. 296-307. Reger, Z. (1986). The functions of imitation in child language. Applied Psycholinguistics 7. 323-52.

Rondal, J. (1980). Verbal imitation by Down's syndrome and nonretarded children. American Journal of Mental Deficiency 85. 318-21.

Scarborough, H. (1985). Measuring syntactic development : the Index of Productive Syntax. Paper presented at the Society for Research in Child Development, Toronto, Canada.

(1990). Index of Productive Syntax. Applied Psycholinguistics ix, 1.22

Simon, N. (1975). Echolalic speech in childhood autism. Archives of General Psychiatry 32, 1439-46.

Skinner, B. F. (1957). Verbal behavior. New York : Appleton-Century Crofts.

Snow, C. E. (1972). Mothers, speech to children learning language. Child Development 43. 549-65.

(1981). The uses of imitation. Journal of Child Language 8. 205-12.

Snow, C. E. \& Bates, E. (1984). Individual differences: a cross-language approach. Workshop presented at the Stanford Child Language Forum, Stanford, California.

Stine, E. \& Bohannon, J. N. (1983). Interactions, imitations, and language acquisition. Journal of Child Language 10. 589-603.

Tager-Flusberg, H. (1982). Pragmatic development and its implications for social interaction in autistic children. In D. Park (ed.), The proceedings of the 1981 international conference on autism. Washington DC: NSAC.

Tager-Flusberg, H., Calkins, S., Nolin, T., Baumberger, T., Anderson, M. \& Chadwick-Dias, A. (1990). A longitudinal study of language acquisition in autistic and Down syndrome children. Journal of Autism and Developmental Disorders 20, 1-22.

Tager-Flusberg, H. \& Calkins, S. (1990). Does imitation facilitate the acquisition of grammar? Evidence from a study of autistic, Down syndrome and normal children. Journal of Child Language, 17, 591-606. Made available courtesy of Cambridge University Press 